\section{Der Säuglingsschrei - mehr als nur ein „Alarmsignal“}

Der Schrei des Säuglings ist die erste verbale Kommunikationsform des Menschen. Akustisch betrachtet gleicht der Säuglingsschrei dem Ertönen einer Sirene. Mit einer Grundfrequenz von ca. $400 \mathrm{~Hz}$ und einer deutlichen Modulationsfähigkeit ist der Schrei des Säuglings ein aufmerksamkeitserregendes und durchdringendes Signal.

\section{Die prosodischen Eigen- schaften des Säuglings- schreis}

Betrachtet man den Säuglingsschrei schallanalytisch, zeigt sich, dass das Intonationsmusters des Schreis abhängig ist von der Umgebungssprache des Säuglings. Säuglinge mit Deutsch als Muttersprache zeigen vermehrt ein trochäisch orientiertes Schreimuster mit einer tendenziell fallenden Tonhöhe. Dagegen zeigen beispielsweise französische Säuglinge ein Schreimuster mit einer ansteigen- den Tendenz, ebenfalls orientiert an der jambischen Intonation des Französischen. Die unterschiedlichen Intonationsmuster sind in Abb. $\mathbf{1}$ visuell dargestellt und können unter Tonbeispiel 1 angehört werden.

\section{MERKE}

Säuglinge schreien in dem Intonationsmuster ihrer Muttersprache.

Die Entwicklung und Ausreifung des Gehörs in der 22. Schwangerschaftswoche ermöglicht dem Fötus bereits im Mutterleib die Wahrnehmung von Schall. Aufgrund der dämpfenden Eigenschaften des Fruchtwassers und des den Fötus umgebenden Gewebes können lediglich die suprasegmentalen Merkmale der Sprache der Mutter sowie anteilig die der Umgebungssprache bis zu dem Fötus durchdringen. Somit sind die Intonation und der Rhythmus einer Sprache dem

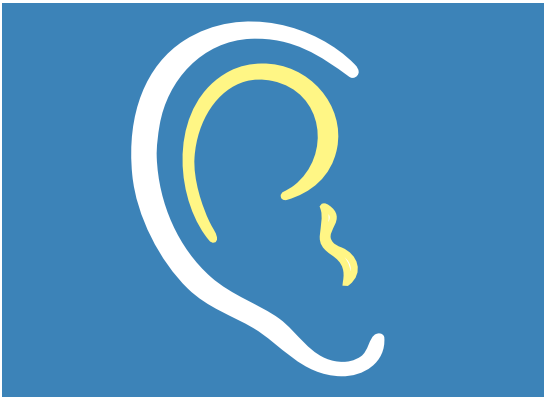

Säugling vorgeburtlich bekannt. Dies äußert sich in den prosodischen Eigenschaften des Säuglingsschreis. Vergleicht man den Schrei von Säuglingen mit einer angeborenen Hörstörung (z. B. einer Schallempfindungsschwerhörigkeit) mit den Schreien von Säuglingen mit einem intakten Gehör, zeigt sich bei Säuglingen mit einer Hörstörung ein Modulationsmuster, welches nicht dem von gesunden Säuglingen entspricht. Der Schrei eines Säuglings mit Hörstörung ist deutlich modulierter, hat eine längere Schreidauer und zeigt beispielsweise keine eindeutige Präferenz zu einem trochäisch orientierten Schreimuster, verglichen mit gesunden Säuglingen. Der Vergleich eines gesunden Schreis und dem eines Säuglings mit Hörstörung ist unter Tonbeispiel 2 zu finden.

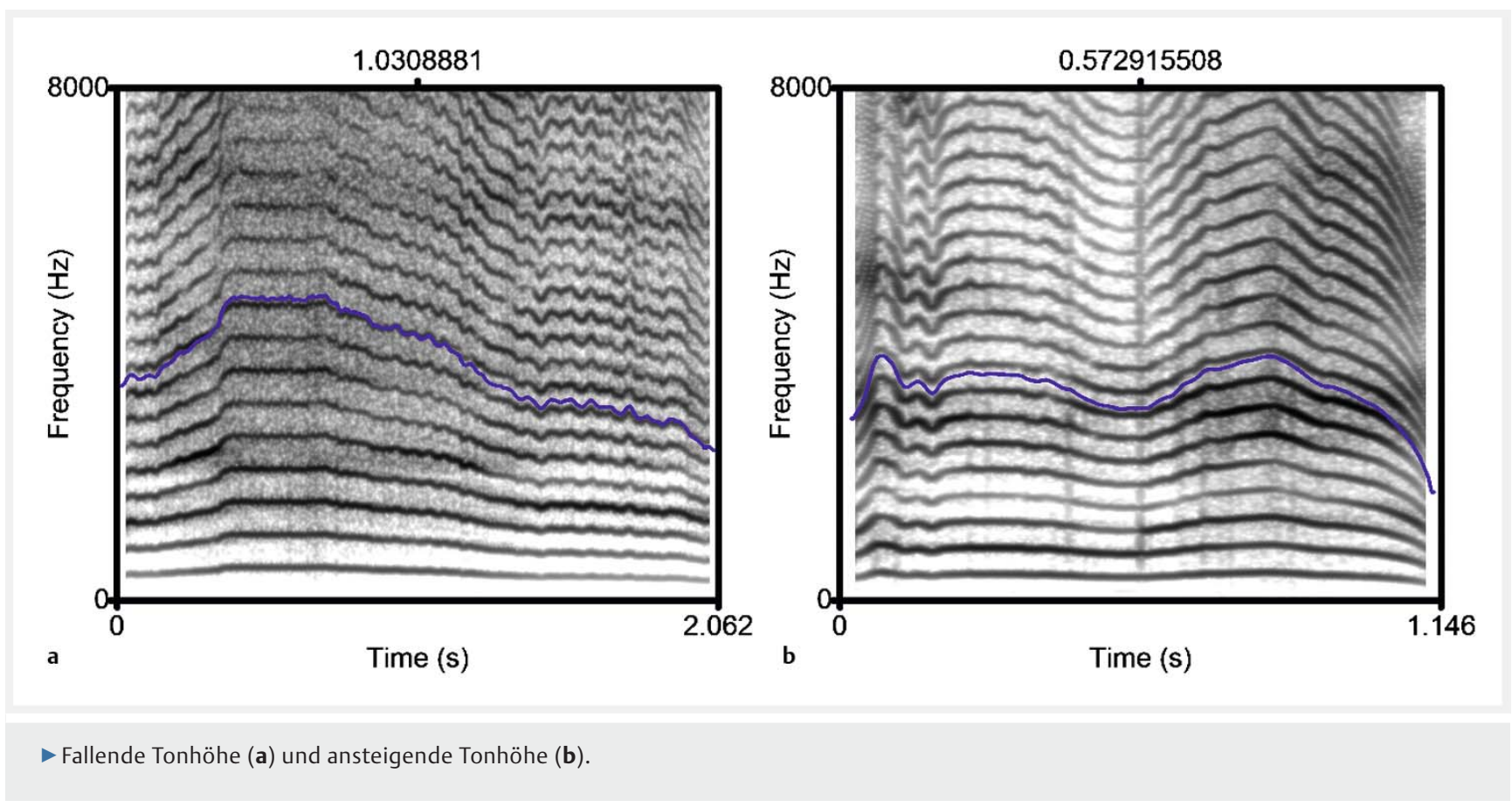




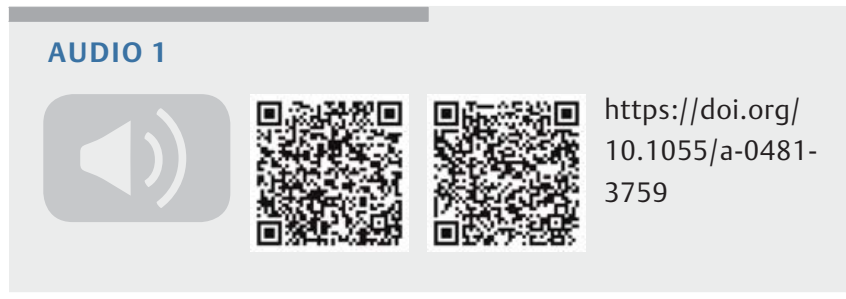

- Audio 1 Intonation fallend (a), Intonation steigend (b).

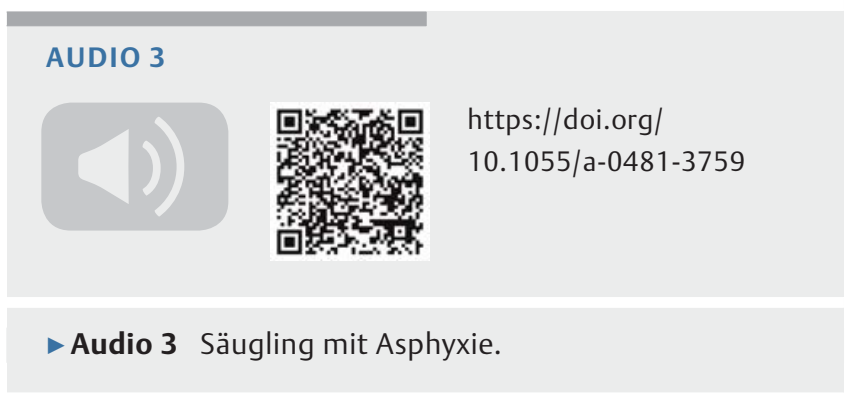

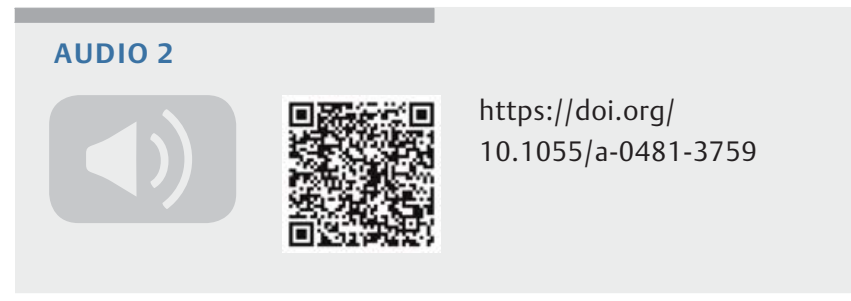

-Audio 2 Säugling mit Hörstörung.

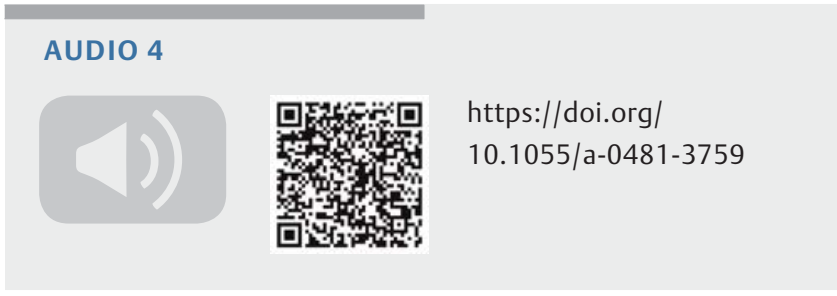

-Audio 4 Säuglinge mit einer Laryngomalazie.

\section{MERKE}

Der Schrei von Säuglingen mit Hörstörungen unterscheidet sich in akustischen und prosodischen Eigenschaften von dem Schrei normalhöriger Säuglinge.

\section{Akustische Eigenschaften des Schreis von verschiede- nen Störungsbildern im Säuglingsalter}

Neben dem Gehör ist auch das System „Stimmgebung“ eines der neuromuskulär am weitesten entwickelten Systeme. Analysiert man die Stimmgebung von Säuglingen mit verschiedenen Störungs- bildern, zeigt sich, dass einzelne Störungsbilder spezifische akustische Eigenschaften aufweisen, die schallanalytisch identifizierbar sind. Säuglinge mit präund perinataler Asphyxie weisen unterschiedliche akustische Eigenschaften wie eine deutlich erhöhte Grundfrequenz und eine erhöhte Mikrovariabilität der Stimmbänder (Jitter) auf (Tonbeispiel 3).

Bei Säuglingen mit einer Laryngomalazie (krankhafte Erweichung des Larynxgewebes) können ebenfalls unterschiedliche akustische Eigenschaften wie vermehrte Stimmabbrüche und Lautstärkeschwankungen identifiziert werden (Tonbeispiel 4).

\section{FAZIT}

Die neuromuskuläre Integrität der an der Stimmgebung und an dem Hörprozess beteiligten Nerven sowie die für die Stimmgebung benötigten Knorpel- und Gewebsstrukturen haben einen direkten Einfluss auf die Stimmgebung im Säuglingsschrei und unterscheiden sich in akustischen Eigenschaften, verglichen mit dem gesunden Säuglingsschrei.

Tanja Fuhr, Henning Reetz, Carla Wegener, Idstein 